// ENTREVISTA

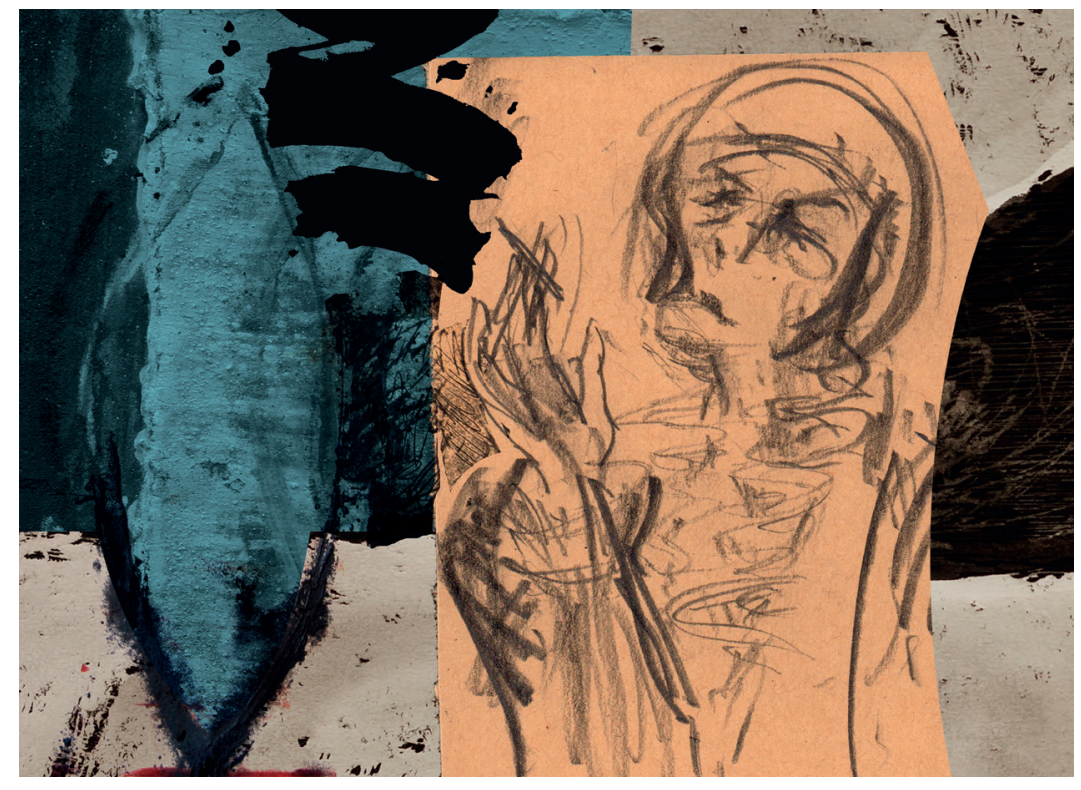


DAVID MARQUÉS

Altered hyperbolae V, 2020

Collage 


\section{Joser Palomero}

ENTREVISTA DE CARLES FENOLLOSA

IL·LUSTRACIONS DE DISSENYINTENS

\section{«La literatura de circumstàncies es fa vella molt a pressa»}

Hi ha poca gent que conega millor que Josep Palomero i Almela (Borriana, 1953) el cosmos cultural valencià dels darrers quaranta anys. Filòleg de formació, ha repartit els seus esforços en diversos fronts, des de la docència inicial, als posteriors projectes de gestió en l'àmbit polític i institucional. És també autor d'una extensa obra, novament diversa, que abasta des de la poesia dels primers anys a les darreres novel-les i assaigs, passant pel teatre. Va rebre, entre d'altres, el Jordi de Sant Jordi de poesia (1980) i l'Eduard Escalante de Teatre (2001), el Tirant lo Blanc de narrativa juvenil (1982), el València de Literatura de novel-la (1983), el Premi de la Crítica dels Escriptors Valencians (1994) i el Ciutat d'Alzira de novel-la (1996). Una trajectòria, doncs, que permet fer balanç des de dins de quatre dècades que han canviat el país.

Poesia, narrativa, teatre, adaptacions, estudis, manuals d'ensenyament... Tem haver diversificat massa la seua producció?

Certament, tinc la impressió que, en compte de córrer cent metres en una mateixa direcció, he corregut un metre en cent direccions diferents. La vida té etapes distintes, i en cada una he fet allò que m'ha atret més. Potser m'hauria 
agradat fer alguna altra novel·la, sí, però el resultat és el que és i no es pot canviar. No obstant, encara cove projectes.

Quins?

Els projectes són matèria reservada, elements de la intimitat i, francament, preferiria no mencionar-los. Un projecte anunciat és un projecte malgastat. No obstant, podria indicar, per exemple, que està pendent de novel·lar l'infortuni de l'exili valencià de la guerra civil, que conec bé perquè vaig dedicar la meua tesi al cas del periodista Artur Perucho, que va nàixer a Borriana i va morir exiliat a Mèxic.

El seu primer llibre fou de poemes, i l'únic en castellà, Una untada de mostaza. Però deixà prompte aquesta llengua, i tampoc no continuà del tot amb la poesia. Com fou aquest procés?

De joves, ignoràvem que la llengua que parlàvem poguera ser també una llengua literària. Als salesians de la meua etapa escolar el valencià no existia en l'aula, però sí en el pati, al revés d'ara. En canvi, un poeta jove, en castellà, sabia en quin marc s'enquadrava, què podia imitar. Una untada de mostaza el vaig escriure el 1970 a París, on vaig passar mig any. És un llibret creatiu i audaç, molt modern per a l'època. En valencià, en canvi, no vaig ser tan atrevit, per més que Piera em qualificara com "el més barroc dels poetes valencians" en Valencia Semanal per Innocents de pagana decadència. Certament, eixe llibre, escrit quan estava de moda l'anomenat formalisme que provenia de la recuperació de Foix, dels Llibres del Mall i dels primers de Bru de Sala, Pinyol, Navarro i Jàfer, estava redactat en un registre massa artificiós. Després, Crònica carnal va correspondre al mestratge d'Estellés i al realisme i, més avant, vaig fer una poesia descriptiva no personal en La rosa dels vents. Finalment, vaig abandonar el gènere. Crec que si algun dia torne a fer versos elucubraré sobre la vida, però dubte que les meues especulacions tinguen gens d'interés. Com a poeta, no sóc autor d'una obra consistent, i ni estic ni se m'espera.

REVISTA VALENCIANA DE FILOLOGIA / IV (2020) p. 253-266

ENTREVISTA A JOSEP PALOMERO DE CARLES FENOLLOSA / 254 
En la seua producció també té articles d'investigació sobre la seua ciutat, Borriana.

Així com de Joan Fuster es va publicar el 1997 Elogi del meu poble, una miscellània de textos sobre Sueca, també jo m'he sentit atret per escriure articles sobre Borriana, la població en què he nascut i on visc, com ara estudis sobre toponímia, antroponímia, cultura popular, història, etc. Precisament ara porte entre mans compilar en un volum tot eixe material dispers, atenent al suggeriment del meu veí Joan Garí, síndic major de l'Agrupació Borrianenca de Cultura i excel·lent escriptor.

Potser on més ressò ha tingut és en l'anomenada "novel-la històrica", especialment als noranta. Deia en una entrevista, a propòsit de la celebrada Els secrets de Meissen (1994) que hi ha "un conjunt d'episodis valencians dels últims doscents anys que constitueixen una epopeia d'abast universal". Ho pensa encara? Em vaig quedar curt. Tinc constància d'uns quants episodis pràcticament desconeguts que han transcorregut en terres valencianes al llarg de la història que podrien constituir una trama argumental molt atractiva, i seria oportú aprofitar-los com a marc general en una obra de ficció.

Aquesta obra, per cert, fou adaptada a la pantalla en una minisèrie de TVE de dos capitols de 90 minuts. Com fou allò?

Les produccions cinematogràfiques es poden realitzar si compten amb un finançament segur. En un moment determinat, això ho va aconseguir el meu amic Enric Viciano, productor de sòlida trajectòria professional, que havia llegit la novel.la i la va trobar amb possibilitats. L'argument el va adaptar Juan Antonio Porto, que ja havia fet, entre d'altres, el guió d'El crimen de Cuenca i de Beltenebros, de Muñoz Molina. La va dirigir Roberto Bodegas, un històric que havia filmat Españolas en París. El repartiment va tindre actors d'anomenada: Omero Antonutti, Nacho Duato, Eusebio Poncela, Sancho Gracia, Juli Mira, Carles Pons, Magüi Mira, Paulina Gálvez. El resultat final em va paréixer molt satisfactori. Es va estrenar en TVE-I el 29 de desembre de 1999 i va obtindre bones crítiques.

REVISTA VALENCIANA DE FILOLOGIA / IV (2020) p. 253-266

ENTREVISTA A JOSEP PALOMERO DE CARLES FENOLLOSA / 255 


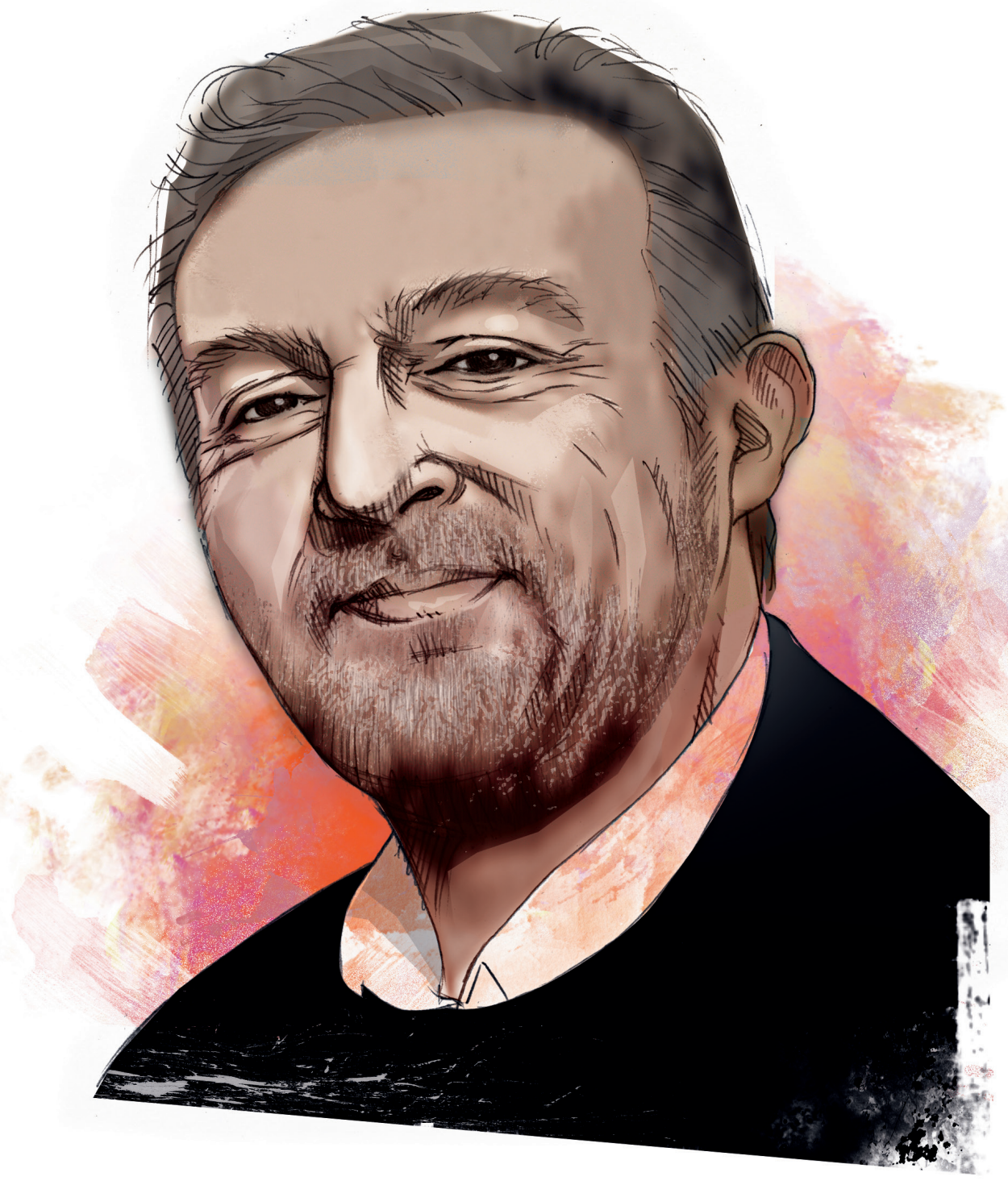

REVISTA VALENCIANA DE FILOLOGIA / IV (2020) p. 253-266

ENTREVISTA A JOSEP PALOMERO DE CARLES FENOLLOSA / 256 
Està d'acord amb el terme de novel.la històrica, per cert? Hi ha qui diu que totes les novel-les són "històriques".

La novel-la històrica és un gènere que va aparéixer en època de Napoleó i que va analitzar György Lukács magistralment. La van cultivar molts escriptors: Walter Scott, Victor Hugo, Stendhal, Anatole France, Romain Rolland, etc. Els lectors considerem històrics els esdeveniments del passat, a partir almenys de dos o tres generacions cap arrere. En el nostre cas hi ha hagut centres d'interés que han tingut gran poder de seducció sobre els escriptors valencians contemporanis, com ara l'expulsió dels moriscos, les Germanies, la Guerra de Successió, la batalla d'Almansa i tot això. A mi eixos episodis no m'atrauen com a recurs narratiu, potser perquè ja han sigut molt explotats.

Pensa que últimament s'ha refredat la febra dels noranta per aquesta classe d'obres?

En absolut, la novel-la històrica és un gènere molt viu que ha contribuït a recuperar la memòria col-lectiva. Diria que és històrica qualsevol narració que emmarque els fets en el passat, no amb l'objectiu de recrear pròpiament la història ni per a explicar-la a través del relat, sinó perquè situa els successos en una època anterior a l'actual, més o menys interessant per les seues característiques pròpies. Des d'eixe punt de vista, hi ha uns quants escriptors valencians que han fet novel·la històrica de molta qualitat: Josep Lozano, Martí Domínguez, Joan F. Mira, Josep Franco, Vicent J. Escartí, Eduard Mira, Anna Moner, Tomàs Llopis, Raquel Ricart, Joan Olivares, Ferran García-Oliver, Ferran Cremades, Silvestre Vilaplana, Pasqual Mas, Lluís Miret, i estic segur que me'n deixe uns quants més.

Fora de les aules - que vosté coneix bé, perquè ha exercit de professor-, sembla que el valencià, com a llengua de lectura, continua sent exòtica.

El públic compra més llibres en castellà, són producte d'una indústria més potent i obra d'autors més notoris i promocionats. A més, la modalitat literària del castellà és un registre assumit pels lectors, ni que es tracte d'autors sud-americans, ben al contrari del que passa en el nostre cas, en què el lec-

REVISTA VALENCIANA DE FILOLOGIA / IV (2020) p. 253-266

ENTREVISTA A JOSEP PALOMERO DE CARLES FENOLLOSA / 257 
tor que no coneix les característiques de la llengua literària ni l'idiolecte de l'autor, abandona la lectura perquè la troba plena d'entrebancs i li resulta insatisfactòria. Per altra banda, el nostre mercat editorial està molt compartimentat $i$, en conseqüència, els autors valencians tenen dificultat en ser reconeguts fora del seu àmbit regional, llevat de casos extraordinaris. De fet, de l'edició de Bromera de la meua novel-la El tatuatge dels apàtrides se'n van vendre ací uns milers d'exemplars, però de la mateixa novel·la, amb segell del Cercle de Lectors o de Columna i amb portades diferents, se'n van vendre molt pocs a Catalunya i, paradoxalment, ni tan sols a les Balears, a pesar de ser una novel-la ambientada a Mallorca i protagonitzada per l'arxiduc Lluís Salvador, l'amo de Miramar, que fou un aristòcrata estrambòtic molt popular allà.

\section{Està massa lligada a l'escola la producció literària valenciana actual?}

En la meua experiència docent, pels anys huitanta, vaig tindre grups d'alumnes molt diligents que en un sol curs llegien una dotzena d'obres voluminoses i senyeres de la literatura europea, espanyola i catalana: Molière, Shakespeare, Dostoievski, Ibsen, Quevedo, Galdós, Clarín, Martín Santos, Vargas Llosa, García Márquez, Llull, Joanot Martorell, Rodoreda, Joan Sales, Pla, Fuster, Mira. Tot això se n'ha anat en orris. Com a conseqüència de la irrupció de la tecnologia digital, la literatura ha perdut atractiu com a recurs de la imaginació. El professor Hauf m'ha assegurat que ara, fins i tot els universitaris, opten per unes lectures o altres en funció del nombre de pàgines del llibre, i prefereixen una adaptació d'Eiximenis o del Tirant com les que he fet jo, abans que llegir l'original, que troben massa llarg i avorrit. Inaudit, no? Per altra banda, des dels noranta s'ha publicat molta narrativa orientada a l'àmbit escolar, amb protagonistes adolescents, en què hi ha de tot, obres d'una qualitat notable i altres que no han aportat gran cosa. Lamentablement, això no té solució, perquè serà pràcticament impossible que tornen a haver alumnes que s'eduquen com a grans lectors a base d'obres de referència, el cànon. Fins i tot la Literatura, com a assignatura, s'ha diluit en la de Llengua, com si fora un residu del passat.

REVISTA VALENCIANA DE FILOLOGIA / IV (2020) p. 253-266

ENTREVISTA A JOSEP PALOMERO DE CARLES FENOLLOSA / 258 
Què no s'ha fet en aquestes dècades de Llei d'Ús i Ensenyament perquè la situació siga tan precària com és actualment?

Més que precària, jo diria que és igual de complexa que la societat, en què el valencià ha de competir per a guanyar espais que es troben còmodes en castellà, com ha sigut habitual. ¿Com introduir el valencià en l'Administració de Justícia, les emissores de ràdio comercials, la premsa, la política, el doblatge, per tal d'assolir almenys l'equilingüisme? És complicat. Els esforços dels equips de Política Lingüística, tant en el període ja llunyà de Baltasar Vives, Honorat Ros, Guillem Badenes i Jesús Huguet, com en els més pròxims de Vicent Satorres i Rubén Trenzano, em mereixen tota la consideració perquè en cada moment li han donat un impuls enorme.

I per a on es podria començar?

La llei de la funció pública valenciana preveu que s'acredite la competència lingüística que es requerisca per a treballar en l'Administració. Més del 90\% del funcionariat de la Generalitat Valenciana entén el valencià, encara que el parle només el $60 \%$, segurament a causa de les vacil-lacions dels castellanoparlants que s'han mogut en un entorn laboral monolingüe. Per altra banda, resulta admirable la valencianització que en els últims anys s'ha fet en totes les administracions, en especial l'educativa, la cultural, la sanitària i també la local, encara que no s'haja avançat tant en l'Administració Perifèrica de l'Estat. El 2007, el ministre Jordi Sevilla va promoure en el Ministeri d'Administracions Públiques el reial decret pel qual es van crear el Consell de les Llengües Oficials i l'Oficina per a les Llengües Oficials. Vaig formar part del grup d'experts que va elaborar eixa norma, però desconec com ha evolucionat, perquè a partir d'un moment determinat el ministre va cessar i els meus contactes van ser revocats i es van dispersar.

Creu que el govern valencià de centreesquerra ha canviat algun aspecte substancial en els darrers anys a nivell de política lingüistica?

Sobretot, han exhibit públicament que la seua llengua és el valencià. El fet de comptar amb una direcció general específica que, a més, coordina la Comis-

REVISTA VALENCIANA DE FILOLOGIA / IV (2020) p. 253-266

ENTREVISTA A JOSEP PALOMERO DE CARLES FENOLLOSA / 259 
sió Interdepartamental per a l'Ús del Valencià, és un instrument molt eficaç per a impulsar polítiques de promoció i recuperació de l'idioma. No em correspon enumerar les accions que s'han dut a terme, però almenys citaré que s'han adaptat les proves de la Junta Qualificadora al Marc Europeu Comú de Referència, s'ha aprovat la Llei de Plurilingüisme en el sistema educatiu valencià, s'ha posat en marxa el Pla Integral d'aprenentatge de Llengües per al Professorat, ha augmentat l'oferta de cursos de valencià en les Escoles Oficials d'Idiomes, en la Generalitat i en l'Administració General de l'Estat, s'han fet campanyes institucionals de promoció social del valencià, etc.

Vosté, des del camp de la gestió cultural, va tindre responsabilitats en aquesta Conselleria.

En la meua època, la cultura es va estructurar i es va promocionar per primera vegada en època de Ciprià Ciscar, que fou un conseller excepcional i infatigable, amb idees molt clares. Va comptar amb equips humans molt qualificats que van dur a terme projectes extraordinaris, com la creació de l'IVAM per Tomàs Llorens, la recuperació del Museu de Belles Arts de València, el programa Música 92, que duia Emili Soler, la rehabilitació del Rialto, la construcció del circuit de Xest, la fundació de la Biblioteca Valenciana, la creació de l'Institut Valencià de la Música i de l'IVAECM, de qui és continuador l'actual Institut Valencià de Cultura, i la instauració del Consell Valencià de Cultura, que al principi van presidir Juan Gil-Albert i Vicente Aguilera Cerni, i a on s'ajuntaven erudits com José Antonio Maravall, Lluís Guarner, Enric Llobregat, José Maria López Piñero, Joan Fuster, el cardenal Tarancon, Andreu Alfaro, García Berlanga, etc. $S$ 'ha fet una labor titànica, però a vegades la memòria és molt curta.

També ha sigut vicepresident de l'Acadèmia Valenciana de la Llengua durant dos mandats. Quin valor té la institució?

L'Acadèmia Valenciana de la Llengua és un cresol de sensibilitats lingüístiques que han aconseguit convergir en solucions idònies, amb la qual cosa hem transmés a la societat una imatge de serenitat que ha contribuit a desarborar el conflicte que es va ordir durant la transició. La institució disposa d'un equip

REVISTA VALENCIANA DE FILOLOGIA / IV (2020) p. 253-266

ENTREVISTA A JOSEP PALOMERO DE CARLES FENOLLOSA / 260 
professional molt qualificat, tant en la part administrativa, que dirigeix Agustí Colomer, com en la lingüística, que encapçala Josep Lacreu, i compta amb una corporació de vint-i-un acadèmics especialistes en camps complementaris del coneixement de la llengua.

L'Acadèmia, que col-labora amb l'Institut Cartogràfic Valencià, ha recopilat i supervisa la toponímia valenciana, un dels seus àmbits competencials exclusiu. De fet, ha publicat uns tres-cents fullets de la col-lecció Toponímia dels Pobles Valencians i el voluminós Corpus Toponimic Valencià que, dirigit pel professor Casanova, conté 50.000 topònims i està disponible en la xarxa.

Per altra banda, el Diccionari normatiu valencià es va aprovar el 2014 després de dotze anys de treball, a partir de les propostes de la Unitat de Recursos Lingüisticotècnics i les aportacions d'una comissió de quatre acadèmics, composta per Jordi Colomina, Rafael Alemany, Artur Ahuir i jo mateix. El DNV és un corpus de 100.000 entrades, que s'incrementa telemàticament cada mes. En el transcurs de l'any passat s'han efectuat 15 milions de consultes, amb una mitjana diària d'unes 40.000 .

Des del web de l'AVL també es pot accedir al Portal Terminològic Valencià, una base d'unitats terminològiques específiques i de neologismes que també s'actualitza mensualment. El 2019 va rebre 92.567 consultes. Finalment, el Corpus Informatitzat del Valencià el componen actualment més de 12.000 documents que abasten des del Llibre del repartiment de Jaume I (1275) fins a obres actuals. Es tracta d'un instrument orientat bàsicament a especialistes, que el 2019 va tindre 95.543 consultes.

Cal esmentar, a més, el programa de l'Escriptor de l'Any, en què hem homenatjat amb edicions especials, exposicions i conferències, l'obra dels escriptors valencians de l'edat moderna, Constantí Llombart, Manuel Sanchis Guarner, Francesc Eiximenis, Enric Valor, Teodor Llorente, Vicent Andrés Estellés, Joan Roís de Corella, Carles Salvador, sor Isabel de Villena, sant Vicent Ferrer i, enguany, Carmelina Sánchez-Cutillas. Hem dedicat jornades d'estudi sobre escriptors actuals a Ferran Torrent, Josep Piera, Rodolf Sirera, Raimon i la Nova Cançó, Joan F. Mira i la traducció, Josep Lozano, Emili Rodríguez Bernabeu, Gaspar Jaén i Lluís Alpera.

REVISTA VALENCIANA DE FILOLOGIA / IV (2020) p. 253-266 ENTREVISTA A JOSEP PALOMERO DE CARLES FENOLLOSA / 26I 
Vint anys després de la seua constitució, l'Acadèmia deuria ser més coneguda pel gran públic. Amb iniciatives com "La paraula de la setmana", uns minivídeos populars que es distribueixen per les xarxes socials, esperem arribar cada vegada a més usuaris.

I què pot fer l'Acadèmia per a augmentar l'ús social de la llengua? Sembla que serà el cavall de batalla del segle.

L'Acadèmia Valenciana de la Llengua, creada per les Corts Valencianes, és una de les cinc institucions assessores de la Generalitat. No és un òrgan executiu i, per tant, no té atribucions en matèria de política lingüística, que correspon al govern valencià.

No obstant això, tota la seua activitat té com a principal orientació impulsar l'ús social de la llengua. A tal fi, elabora diccionaris, gramàtiques i repertoris de consulta; normalitza l'onomàstica i la toponímia, assessora les institucions i resol tota classe de consultes lingüístiques; publica textos pertinents, facilita versions dels textos sagrats i litúrgics a les parròquies i divulga els nostres escriptors. Compta, a més, amb una secció específica, la de Foment de l'Ús del Valencià, dedicada especialment a promoure i estimular el valencià en aquells àmbits en què convinga impulsar la seua pràctica normal.

L'Acadèmia manté des de fa anys convenis de col-laboració amb diversos ajuntaments: Alcoi, Alzira, Benicarló, Borriana, Dénia, Elx, Gandia, Vila-real i Vinaròs. A més, té díhuit línies de subvenció que consten en el capítol de transferències corrents del pressupost anual, de les quals són receptors l'Associació d'Editors del País Valencià, la Fundació Escola Valenciana, la Fundació Sambori, la Fundació Bromera per al foment de la lectura, el concurs de teatre amateur Vila de Mislata i el de la Junta Central Fallera, la Federació de Lletres Falleres, la Societat d'Onomàstica, la Unió Gremial, les universitats valencianes, l'Associació Cultural El Tempir, el Col-lectiu l'Esbarzer, la Valencian Music Association; també subvenciona els mitjans de comunicació d'àmbit local o comarcal i les publicacions i revistes d'investigació. En el pressupost de 2020 s'hi han destinat en total 206.600 euros.

REVISTA VALENCIANA DE FILOLOGIA / IV (2020) p. 253-266

ENTREVISTA A JOSEP PALOMERO DE CARLES FENOLLOSA / 262 


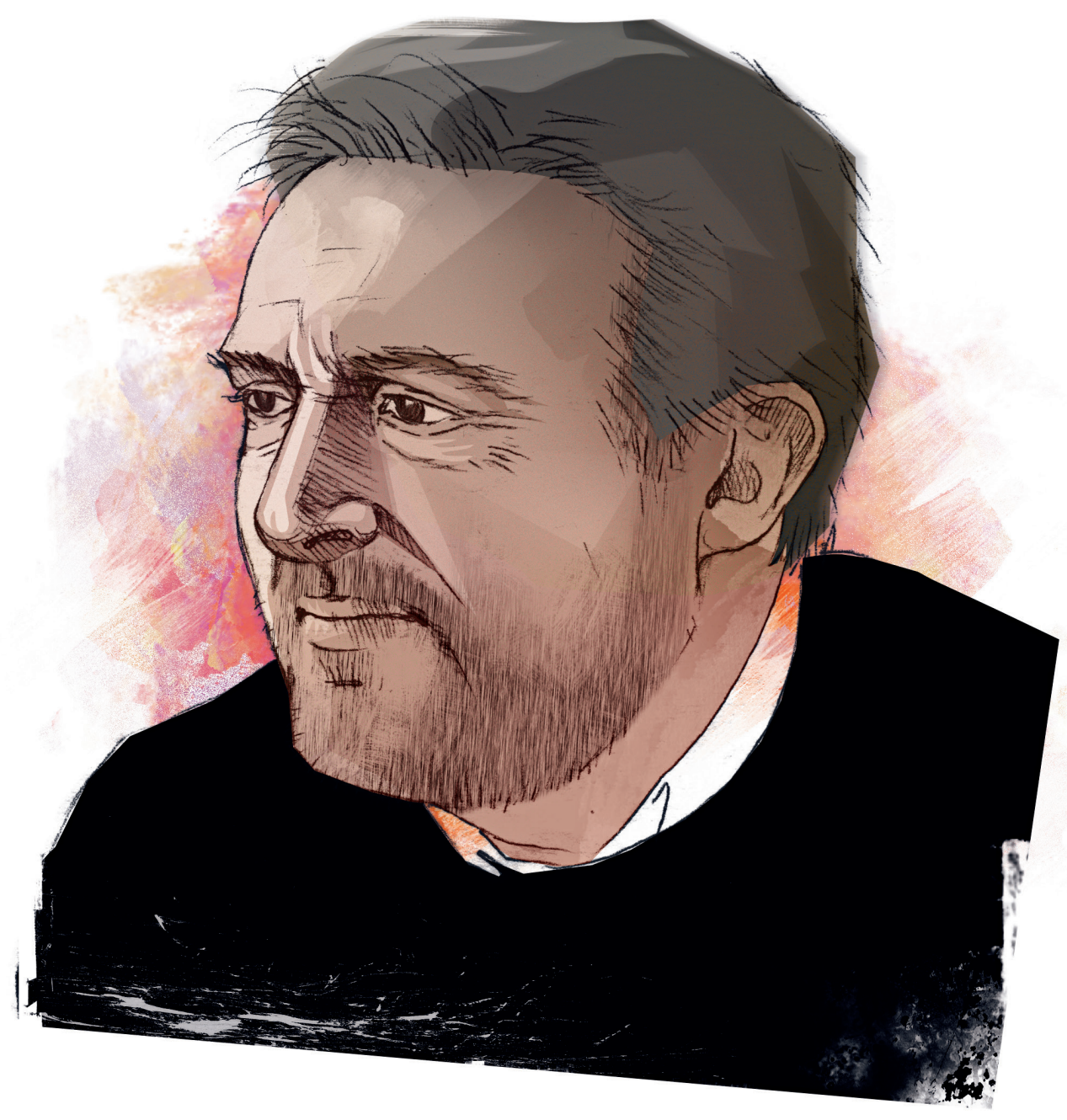

REVISTA VALENCIANA DE FILOLOGIA / IV (2020) p. 253-266

ENTREVISTA A JOSEP PALOMERO DE CARLES FENOLLOSA / 263 
Hi ha també "el tema del sud". Com fer del valencià una llengua seductora, especialment en aquelles zones en què hi ha sectors que la veuen com una mera "imposició", com en el cas del sud d'Alacant?

Entre Vinaròs i Oriola falta més comunicació i més sentiment de pertànyer a un mateix poble. $\mathrm{Al}$ nord, la vitalitat del valencià és inqüestionable. $\mathrm{Al}$ sud, en canvi, perquè el valencià siga una opció seductora caldria, en primer lloc, despolititzar tot allò referit a la llengua i evitar qualsevol conflicte idiomàtic, insistint en el fet que saber valencià és una característica substantiva del conjunt del país.

$\mathrm{Al}$ sud, l'escola ha fet molt, però no pot ser l'únic agent activador. En ocasions, el professorat de valencià del Baix Segura s'ha sentit desemparat en els seus objectius docents, perquè voldria comptar amb un projecte curricular adequat a la particularitat sociolingüística d'eixa comarca. Seria molt convenient que disposara d'un material didàctic específic que estimulara la valoració de la idiosincràsia dels parlars valencians meridionals, en risc de desaparició, a fi que es prestigien al mateix temps que els alumnes aprenen el registre estàndard. En el cas del Baix Vinalopó, seria oportú dispondre d'un estudi sobre les actituds lingüístiques i els usos del valencià a la ciutat d'Elx, ja que el fet d'atraure Elx a la valencianitat lingüística i cultural comporta guanyar gran part del sud.

El fet d'aprendre valencià és útil per a poder tindre més oportunitats laborals, especialment en l'Administració. En l'etapa escolar es té bona capacitat per a estudiar les tres llengües de l'ensenyament alhora i, si instruïm l'alumnat adequadament, sense imposicions, sinó amb convenciment i amb bones pràctiques pedagògiques, assoliran una bona competència i superaran prejudicis.

Creu que hi ha encara un problema de model lingüistic al País Valencià? L'Acadèmia, À Punt i la Universitat fan servir models diferents, per exemple. Més que d'un problema, es tracta d'unes opcions que pràcticament es limiten a l'ús preferent dels demostratius simples o dels reforçats, a l'increment -eix o - $i x$ d'alguns verbs incoatius de la tercera conjugació i a unes determinades preferències en l'elecció lèxica. Probablement l'alternativa més conservadora té a favor seu la coincidència amb la norma escrita del català general, però l'altra,

REVISTA VALENCIANA DE FILOLOGIA / IV (2020) p. 253-266

ENTREVISTA A JOSEP PALOMERO DE CARLES FENOLLOSA / 264 
que és igualment gramatical, és més pròxima al parlar valencià actual i, per això mateix, pareix la més adequada per al registre oral, fins i tot en circumstàncies considerades molt formals.

Sol passar que, quan una persona pública té davant un micro, un altaveu i una càmera de vídeo, si té capacitat per a fer-ho, té tendència a canviar el seu registre oral propi i habitual per un altre més inusual però considerat, erròniament, més culte. Quan això passa, s'incorre en una pràctica diglòssica dins del mateix idioma, com si la forma de parlar pròpia, dins dels límits de la correcció, no fora adequada per a les ocasions solemnes. Al respecte, À Punt pot fer de model i ser un bon exemple.

La lingüista Carme Junyent ha declarat no fa molt que el català és una llengua en procés d'extinció. És vosté tan pessimista?

La professora Junyent és una autoritat en el camp de les llengües amenaçades, és autora d'una bibliografia acreditada i està facultada per a expressar eixa classe d'opinions. El món actual, connectat tan estretament, necessita instruments comunicatius cada vegada més globals que reemplacen les llengües minoritzades. Per demografia, estatus jurídic, situació sociolingüística i normativa legal, la nostra llengua, s'anomene valencià o català, és la més nombrosa de les que la UE considera regionals o minoritàries perquè no tenen rang d'oficialitat en tot l'Estat. També és més parlada que algunes llengües oficials europees. Els anys 2006 i 2007 vaig formar part del Grup d'Alt Nivell sobre Multilingüisme de la Comissió Europea i el meu report sobre "Obstacles específics per a la promoció de les llengües regionals i minoritàries", que vaig elaborar en colllaboració amb Miquel Strubell i altres experts, va ser rebut amb molta animadversió per part del comissari de Multilingüisme, que presidia la sessió, el romanés Leonard Orban, contrari a la més mínima insinuació d'introduir qualsevol modificació en el tractat fundacional, que només contempla l'ús de les llengües que són oficials de tot el territori de cada Estat de la Unió. Això passa, paradoxalment, en el cas del gaèlic irlandés, que a la República d'Irlanda parlen només unes 70.000 persones, o del maltés, que és cooficial a la República de Malta i té mig milió de parlants, mentre que la nostra llengua en té teòricament 10 milions.

REVISTA VALENCIANA DE FILOLOGIA / IV (2020) p. 253-266

ENTREVISTA A JOSEP PALOMERO DE CARLES FENOLLOSA / 265 
Per tant...

Per tant, no crec que el pronòstic de la professora Junyent siga factible, almenys en les pròximes dècades. Una altra cosa seria plantejar si serà viable el manteniment de la qualitat genuïna de la llengua, tan rica dialectalment, afectada pels processos d'empobriment derivats de l'estandardització a què la sotmeten els media. Això sí que és imparable, però ens podem resignar perquè és un fenomen que passa en totes les llengües del món.

Es considera una persona optimista?

He sigut sempre molt optimista, a vegades massa i tot. Cada projecte que he emprés l'he fet amb convicció, confiança en mi mateix i respecte als altres. Si com a escriptor de ficció no he produït tant com potser hauria sigut possible és perquè tinc tendència a la dispersió i m'he distret en altres facetes de la vida que m'han resultat atractives. No m'ha agradat mai perdre el temps escrivint coses inútils. En certa ocasió el director d'un diari em va demanar un pròleg per a una enciclopèdia de Castelló en fascicles col-leccionables que em va costar dos o tres dies d'escriure. Quan li'l vaig presentar el va llegir em diagonal en mig minut. En manifestar la meua sorpresa em va contestar que allò que publiquen els diaris dura només fins a la nit, i aleshores vaig comprendre que, per ànsia de publicar, escrivim massa coses supèrflues que tenen poc d'interés i que la literatura de circumstàncies es fa vella molt a pressa.

REVISTA VALENCIANA DE FILOLOGIA / IV (2020) p. 253-266

ENTREVISTA A JOSEP PALOMERO DE CARLES FENOLLOSA / 266 